\title{
Articulação teórico-prática em um currículo de um curso de Enfermagema
}

\author{
Theoretical-practical articulation in a curriculum of a Nursing course \\ Articulación teórico-práctica en un currículo de un curso de Enfermería
}

Vânia Aparecida da Costa Oliveira ${ }^{1}$ (1)

Maria Flávia Gazzinelli² (D)

Patrícia Peres de Oliveira ${ }^{1}$ (c)

1. Universidade Federal de São João del-Rei. Divinópolis, MG, Brasil.

2. Escola de Enfermagem. Universidade Federal de Minas Gerais. Belo Horizonte, MG, Brasil.

\section{RESUMO}

Objetivo: Compreender como a articulação teórico-prática se efetiva num currículo de um curso de graduação em Enfermagem. Método: Trata-se de um estudo de caso único, com abordagem qualitativa, desenvolvido por meio de análise documental e por entrevistas individuais com roteiro semiestruturado com dez docentes e 14 discentes entrevistados no período de fevereiro a maio de 2015. A análise dos dados foi realizada segundo os pressupostos da Análise Crítica do Discurso. Resultados: Os dados revelaram a existência de tensões e ambivalências entre duas formas de relação entre teoria e prática. A primeira, relacionada à teoria-prática como unidade indissolúvel e a segunda à visão da teoria e prática como instâncias dicotômicas e predomínio da teoria precedendo a prática. Conclusões e implicações para a prática: Há fragilidades na efetivação da articulação teórico-prática no currículo do curso de Enfermagem investigado, evidenciando a supremacia do paradigma cartesiano no ensino superior de Enfermagem. Dessa forma, torna-se premente instituir estratégias que viabilizem a indissociabilidade teórico-prática no currículo.

Palavras-chave: Enfermagem; Curso de Enfermagem; Currículo; Ensino.

\section{ABSTRACT}

Objective: To understand how the theoretical-practical articulation is effective in a curriculum of an undergraduate Nursing course. Method: This is a unique case study, with a qualitative approach, developed through document analysis and individual interviews with semi-structured script with 10 teachers and 14 students interviewed from February to May 2015. Data analysis was performed according to the assumptions of Critical Discourse Analysis. Results: The data revealed the existence of tensions and ambivalences among two forms of relationship between theory and practice. The first, related to theory-practice as an indissoluble unit and the second, to the view of theory and practice as dichotomous instances and the predominance of theory preceding practice. Conclusions and implications for practice: There are weaknesses in the implementation of theoretical and practica articulation in the curriculum of the Nursing course investigated, showing the supremacy of the cartesian paradigm in higher education in Nursing. Thus, it is urgent to institute strategies that enable the theoretical-practical inseparability in the curriculum.

Keywords: Nursing; Nursing Course; Curriculum; Teaching.

\section{RESUMEN}

Objetivo: Comprender cómo la articulación teórico-práctica es efectiva en un plan de estudios de un curso de pregrado en Enfermería. Método: Este es un estudio de caso único, con enfoque cualitativo, desarrollado a través del análisis de documentos y entrevistas individuales con guiones semiestructurados con diez maestros y 14 estudiantes entrevistados de febrero a mayo de 2015. El análisis de datos fue realizado de acuerdo con los supuestos del análisis crítico del discurso. Resultados: Los datos revelaron la existencia de tensiones y ambivalencias entre dos formas de relación entre teoría y práctica. El primero, relacionado con la teoría-práctica como una unidad indisoluble y el segundo con la visión de la teoría y la práctica como instancias dicotómicas y el predominio de la teoría que precede a la práctica. Conclusiones e implicaciones para la práctica: Existen debilidades en la implementación de la articulación teórica y práctica en el currículo del curso de Enfermería investigado, lo que demuestra la supremacía del paradigma cartesiano en la educación superior en Enfermería. Por lo tanto, es urgente establecer estrategias que permitan la inseparabilidad teórica y práctica en el currículo.

Palabras clave: Enfermería; Educación en Enfermería; Curriculum; Enseñanza.
Autor correspondente:

Vânia Aparecida da Costa Oliveira E-mail: profvaniaufsj@ufsj.edu.br

Recebido em 30/10/2019.

Aprovado em 26/02/2020.

DOI:

https://doi.org/10.1590/2177-9465-EAN-2019-0301 


\section{INTRODUÇÃO}

No Brasil, a formação superior de Enfermagem vem sendo instada, ao longo dos últimos anos, a suplantar o modelo de ensino tradicional ancorado na visão fragmentada e unidimensional da realidade e do conhecimento e na perspectiva biologicista do processo saúde-doença. ${ }^{1}$ Nesse contexto, a reformulação de Projetos Pedagógicos de Cursos (PPC)e de currículos tem sido fomentada pelas Diretrizes Curriculares Nacionais (DCN) para os Cursos de Enfermagem, instituídas por meio da Resolução no 3/2001, do Conselho Nacional de Educação (CNE) e Câmara de Educação Superior (CES). ${ }^{2}$

As DCN para os cursos de Enfermagem representam, então, um marco rumo às mudanças na formação do enfermeiro. ${ }^{3}$ O texto das DCN para os cursos de Enfermagem defende que essa formação deva se dar consoante às necessidades do Sistema Único de Saúde (SUS) e aos problemas de saúde da sociedade contemporânea. ${ }^{4}$ Para tanto, faz-se necessária a adoção de uma educação inovadora, que considere o princípio da formação integral e da interdisciplinaridade e que assegure a articulação ensino-serviço e teoria-prática, ${ }^{5,6}$ nos diferentes contextos da prática profissional do enfermeiro; num movimento de ação-reflexão-ação; como estratégia do dia a dia do ensinar e aprender em enfermagem. Nessa perspectiva, tal prática surge como problematizadora do processo de construção de conhecimento do futuro enfermeiro. ${ }^{7}$

Em que pese os avanços na formação do enfermeiro desde a instituição das DCN para os cursos de Enfermagem, importantes desafios ainda precisam ser enfrentados para o alcance da formação almejada. Dentre eles, destaca-se, neste estudo, o de dar concretude à proposição da articulação teoria-prática como uma unidade indissolúvel. 8,9

Estudos evidenciam que tal proposição ainda não ocorre como deveria, sendo, com frequência, sobrepujada por entendimentos simplistas que ora valorizam a teoria, ora valorizam a prática. ${ }^{10,11} \mathrm{Em}$ termos do currículo, isso significa adotar um desenho curricular em que haja uma alternância entre disciplinas ou atividades teóricas e disciplinas ou atividades práticas. Com isso, pressupõe-se que os estudantes são capazes, por si mesmos, de integrar teoria e prática. ${ }^{12} \mathrm{Em}$ consequência disso, não raro, constatam-se insatisfações por parte de estudantes e ou egressos, que relatam divergências entre o que é ensinado durante as aulas e o que se vivencia no cotidiano da prática. ${ }^{10,11,13}$

Nesse sentido, a compreensão de como é efetivada a articulação entre a teoria e a prática em um currículo de um curso de enfermagem mineiro após 17 anos de DCN para os cursos de Enfermagem, emerge como uma prioridade, ao se considerar o momento atual vivido pelos Cursos de Graduação em Enfermagem, com novas DCN a serem aprovadas pelo Ministério da Educação. Frente a essas considerações, cabe perguntar: como ocorre a articulação entre a teoria e a prática em um currículo de um curso de enfermagem de uma universidade mineira?

Com o objetivo de compreender como a articulação teórico-prática se efetiva em um currículo de um curso de enfermagem, essa pesquisa assume um caráter necessário e relevante, na medida em que pretende contribuir com a reflexão sobre do processo de formação do enfermeiro, no que tange à articulação teórico-prática, como forma de subsídio para a reorientação do fazer e saber, no desafiante caminho da implementação da mudança na educação em enfermagem no mundo contemporâneo.

\section{MÉTODO}

\section{Aspectos éticos}

A presente investigação atendeu a todos os requisitos éticos e legais de pesquisa envolvendo seres humanos no Brasil. O projeto foi cadastrado na Plataforma Brasil, submetido ao Comitê de Ética em Pesquisa da Universidade Federal cenário do estudo, sendo aprovado sob o Protocolo CAAE 34540614.3.0000.5149 e Parecer $n^{\circ}$ 938.681.

\section{Tipo de estudo}

O trabalho constitui-se num estudo de caso, do tipo único, de abordagem qualitativa. O estudo de caso é um método adequado para as pesquisas que buscam entender os fenômenos sociais complexos e contemporâneos, com o intuito de conhecê-los em profundidade, considerando os contextos reais nos quais eles ocorrem. ${ }^{14}$

\section{Cenário do estudo}

O presente estudo tem como foco o currículo do Curso de Graduação em Enfermagem de uma Universidade Pública mineira, que passou, como todas as outras instituições educacionais, por um processo de mudança a partir da regulamentação das DCN para os cursos de Enfermagem.

\section{Coleta e organização dos dados}

Os dados foram coletados por meio da análise documental do PPC e outros documentos afins, como as matrizes curriculares disponíveis no site da instituição pesquisada e por meio de entrevistas com roteiro semiestruturado composto por perguntas sobre como a articulação teoria-prática se efetivava no currículo vigente da instituição de ensino.

Os participantes da pesquisa foram dez docentes e 14 discentes, que atenderam aos seguintes critérios de inclusão: a) docente efetivo desde o ano de 2009, quando foi implantado o currículo vigente; b) discentes regularmente matriculados no último período do curso, que equivale ao décimo período do primeiro semestre de 2015, época de início da coleta dos dados. A opção por entrevistar os discentes do décimo período se deu por entender que eles poderiam ter uma visão mais ampliada do currículo, uma vez que estão finalizando o percurso formativo.

Para a obtenção de uma participação mais uniforme dos docentes, foi definida a participação de um docente por área de atuação. Para tanto, cada um dos três departamentos da instituição: Enfermagem Básica, Enfermagem Aplicada e Enfermagem Materno-Infantil e Saúde Pública forneceu um relatório em que 
constava o número de docentes e a respectiva área de atuação, sendo elas: saúde coletiva, saúde pública/atenção básica epidemiologia, fundamentos de Enfermagem, saúde da mulher e do recém-nascido, saúde da criança e adolescente, saúde do adulto e idoso, saúde mental, educação em enfermagem e administração em enfermagem. Posteriormente, realizou-se, então, o sorteio dos dez docentes.

O contato com os docentes para a participação na pesquisa se deu via endereço eletrônico, disponível no site da instituição e fornecido pelos departamentos. O contato consistiu de um convite para a participação na pesquisa, com a apresentação das pesquisadoras, bem como do objeto de estudo e seus objetivos. Após a aceitação, as entrevistas foram agendadas de acordo com a disponibilidade de data e horário de cada docente, realizadas nas suas respectivas salas, no período de fevereiro a maio de 2015 e tiveram uma duração média de 26 minutos e um total de quatro horas e vinte e cinco minutos.

Para a participação dos discentes, solicitou-se à seção de ensino um relatório constando o número de alunos matriculados no décimo período do primeiro semestre de 2015 e seus respectivos contatos. O relatório indicou que 26 discentes encontravam-se matriculados nesse período. O início das entrevistas deu-se mediante a realização de um sorteio. Os discentes sorteados foram contatados por meio telefônico e por endereço eletrônico. De forma análoga aos docentes, os discentes foram convidados a participar da pesquisa, respeitando-se a disponibilidade individual de dia e horário. As entrevistas foram realizadas nas áreas livres da instituição, no período de fevereiro a abril de 2015, e tiveram uma duração média de 10 minutos, totalizando duas horas e dezoito minutos. A definição do número de discentes participantes obedeceu ao princípio da saturação empírica. ${ }^{15}$

As entrevistas foram gravadas, após anuência dos participantes no Termo de Consentimento Livre e Esclarecido, e posteriormente transcritas. Para manter a ética e o compromisso de garantir o anonimato, os docentes foram nomeados de "Do", utilizando-se a sequência Do1 a Do10, e os discentes de "Di", seguindo a sequência de Di1 a Di14.

\section{Análise dos dados}

Os dados foram submetidos à Análise Crítica do Discurso (ACD) proposta por Fairclough. ${ }^{16}$ Esse autor defende a relação dialética entre discurso e estrutura social, ou seja, se por um lado, o discurso é moldado e restringido pela estrutura social, por outro ele é socialmente constitutivo, presente em todas as dimensões da estrutura social. Para a ACD o discurso é uma forma pela qual as pessoas podem agir sobre o mundo e, especialmente sobre os outros, como também um modo de representação. Dessa forma, é fundamental que a análise do texto englobe aspectos que podem ser investidos ideologicamente, como os sentidos das palavras, as pressuposições e metáforas.

Diante disso, as entrevistas foram transcritas de forma mais detalhada possível, consideradas as manifestações dos participantes no momento das entrevistas. A seguir, realizou-se leitura exaustiva dos discursos transcritos com análise compreensiva e identificação de discursos semanticamente semelhantes que pudessem ser relacionados entre si e, dessa forma, dar origem a categorias empíricas. As categorias empíricas foram analisadas de forma crítica, de modo a captar os sentidos e significados dos discursos produzidos pelos participantes, por meio de uma análise individualizada de cada excerto. Por fim, buscou-se um diálogo das categorias empíricas com os dados advindos do Projeto Pedagógico de Curso da instituição.

A análise dos dados acerca da efetivação da articulação teórico-prática possibilitou a construção de uma única categoria empírica, intitulada: Tensões e ambivalências entre unidade teórico-prática e teoria e prática.

\section{RESULTADOS}

\section{Tensões e ambivalências entre unidade teórico-prática e teoria e prática}

Os discursos revelaram a existência de duas formas de relação entre teoria e prática. A primeira, diz respeito à teoria-prática como uma unidade simultânea e indissolúvel, e a segunda relaciona-se com a visão da teoria e prática como instâncias dicotômicas.

Percebeu-se que alguns docentes apresentam discursos mais próximos à primeira relação, dessa forma, revelam uma prática pedagógica que não desvencilha a teoria da prática, o que permite valorizar as experiências vivenciadas pelos estudantes, como pode-se observar nos excertos abaixo:

[...] É natural que quando eu estou em processo de ensino eu tenha uma intencionalidade. Não é por acaso que eu faço. Então, existe uma intencionalidade, eu tenho clareza de que na hora em que eu estou trazendo um conhecimento, eu estou articulando ele para a prática. [...] A questão é buscar situações que exijam essa articulação, por exemplo, situações que são reais, situações que são vividas (Do2).

[...] Essa articulação teoria e prática eu tento integrar da seguinte maneira: sempre tentando ensinar o conhecimento teórico o quanto possível já no cenário de prática [...] Muitos dos conhecimentos que não foram possíveis de serem lecionados dentro da sala de aula, a gente tenta fortalecer no cenário de prática, com situações reais vivenciadas pelos alunos (Do1).

[...] Eu tento fazer discussões com os alunos a partir das vivências e situações que eles vivenciam na prática. Então, eles trazem os problemas e eu peço para eles teorizarem em cima e a gente debate. Tem algumas estratégias de ensino que a gente adota, por exemplo, grupos de discussão [...] O portfólio é outra estratégia que a gente utiliza muito [...] Os portfólios são mensais, relatos de situações de atendimentos, situações da prática profissional, situações concretas que eles vivenciaram [...] (Do10). 
Observou-se que Do2 expressa um agir pedagógico reflexivo, em que pensamento e ação caminham juntos. Dessa maneira, suas ações não são feitas por acaso, há uma intenção que visa tornar o processo ensino-aprendizagem significativo para o aluno, por isso, não prescinde da experiência deste. Os demais docentes também alegam que asseguram a articulação entre teoria e prática, ao tomarem as situações concretas como substratos para as discussões teóricas. Vê-se que Do1 usa o termo "sempre" para mostrar que, na sua prática pedagógica, não se descuida dessa articulação.

O docente Do6, ao usar a metáfora "bandeira na mão", sugere acreditar plenamente na articulação teoria e prática:

Bom, isso eu defendo de bandeira na mão. Tanto nas disciplinas de Fundamentos como em Primeiros Socorros a gente sempre está articulando a teoria e a prática. Mesmo que seja aplicar uma injeção o aluno tem que saber o que ele está fazendo, qual é o agravo que o paciente tem, quais são os efeitos colaterais. Pode ser encaminhar o paciente para o banho, a gente já fala da questão do exame físico que vai ser realizado. Isso para mim é muito tranquilo, é muito nítido (Do6).

Em seu discurso, Do6 demonstra sempre cuidar para que essa articulação ocorra. Percebe-se que, para o docente, é importante que o estudante entenda a racionalidade científica que orienta toda a prática do enfermeiro. Desse modo, é importante saber o que se faz, quando se faz e por que se faz.

A partir desses discursos, identifica-se que a busca pela efetivação da relação teórico-prática como unidade indissociável permeia o agir pedagógico dos docentes, que contextualizam as situações cotidianas ocorridas nos cenários de prática, entrelaçando-as com discussões teóricas.

Outros docentes, por sua vez, apresentam discursos em que se pode identificar a visão aplicacionista, em que a teoria precede a prática:

[...] Falar de minha prática docente em termos do princípio da articulação teoria e prática, eu acho que é muito tranquilo. É uma prática incorporada. A nossa disciplina, ela tem uma carga horária prática que é o triplo da teórica, então isso facilita essa articulação teoria e prática. Nós somos da teoria e somos da prática, então, vejo que isso é um avanço no nosso currículo. Então, tudo que a gente vê na teoria que é bem resumida a gente leva para a prática. Eu vejo que está bem avançada e bem consolidada essa questão da teoria e prática no currículo. Na minha atuação, isso é bem tranquilo (Do3).

[...] Na minha prática docente na área da Administração eu entendo que essa articulação ocorra. A gente tem uma carga horária prática que contextualiza aquilo que foi discutido em sala de aula, da melhor maneira possível. Mas, eu acho que ela deveria ser um pouco mais, falta uma pactuação maior, uma aproximação maior dos professores com os cenários de prática. A disciplina tem uma carga horária prática de 30 horas, se você pegar a carga horária que efetivamente a gente vai lá, e eu já questionei isso várias vezes, não perfaz as 30 horas. A carga horária não é cumprida da maneira que deveria [...] arruma-se um jeito do aluno ficar menos no campo, se você me perguntar por que, eu não sei (Do5).

Percebe-se que a prática é a instância de aplicação do conhecimento teórico, portanto uma compreensão de que primeiro se adquire conhecimentos para, posteriormente, aplicá-los. Essa assertiva pode ser evidenciada na fala de Do3 quando diz: "[...] Tudo que a gente vê na teoria que é bem resumida a gente leva para a prática". Já na fala do docente Do5, destaca-se o fato de haver diminuição de carga horária prática, que, por motivos não revelados, implica em menos tempo de imersão do aluno no campo de prática.

A seguir, os discursos dos discentes somam-se aos discursos dos docentes, na reafirmação da visão aplicacionista:

[...] A integração entre o conteúdo teórico e o conteúdo prático existe na maioria das disciplinas, então, sempre a gente tem um conteúdo teórico depois a gente vai para o campo colocar em prática, então, por exemplo, em Saúde da Criança a gente vai para o posto de saúde fazer as consultas de puericultura, Saúde da Mulher a mesma coisa, a gente tem a oportunidade de fazer os exames de Papanicolau, de atender a mulher e de fazer pré-natal. Então, eu acho que com isso não tem nenhum problema, a maioria das disciplinas a gente tem essa integração do conteúdo com a prática (Di2).

Tem, basicamente sim. Os campos de estágio são muito ricos, e sempre voltados para o que eles deram, a gente via muito isso, o professor falava lá na teoria e a prática vinha e confirmava o que tinha sido dito, então, eles estão sendo fiéis ao que é basicamente a prática assim, então, é muito bom [...] (Di3).

Sim, esse eu acho que sim, principalmente pela forma como é organizado também no Estágio, às vezes a gente tem um conteúdo e depois vai para a prática [...] A gente fica muito na teoria e pouco prática, eu não me sinto preparada, eu não me acho enfermeira entendeu? E eu estou formando agora, eu não me sinto preparada para diversas coisas [...] (Di12).

Mais ou menos [...] porque [...] a gente teve toda disciplina teórica, principalmente Enfermagem Clínica no sexto período, a gente teve toda teoria em sala de aula e foi para o campo, só que a gente não teve tempo de estudar porque a disciplina é muito curtinha, então veio aquele tanto de patologia, veio aquele tanto de sabedoria que a gente tinha acabado de ver em Fundamentos, que nem todo mundo teve a oportunidade, por exemplo, punção eu fiz só duas punções até hoje, eu estou tendo 
dificuldade principalmente nessa parte da prática, falta-me experiência. [...] Acaba que eles jogam na gente aquele tanto de teoria, aí chega na hora da prática eles querem que a gente faça aquilo sem a gente saber, não dá tempo de estudar [...] (Di5).

Os discentes acreditam na efetivação da articulação entre teoria e prática, que desponta como relevante na medida em que possibilita a realização de procedimentos e técnicas próprias do exercício do enfermeiro, como consulta de puericultura, de pré-natal, ginecológica, entre outros. É perceptível a primazia da teoria. O seguinte trecho da fala de Di3: "O professor falava lá na teoria e a prática vinha e confirmava o que tinha sido dito, então, eles estão sendo fiéis ao que é basicamente a prática" é exemplar para confirmar que a prática ganha relevância na medida em que é fiel aos parâmetros da teoria.

A análise documental da matriz curricular de 2015 mostra que, de forma geral, o planejamento das disciplinas mantém a lógica da teoria precedendo a prática. Tal constatação fica evidente nas disciplinas: Enfermagem psiquiátrica, Capacitação pedagógica, Epidemiologia, Gestão do sistema de saúde, Gerência em saúde e em Enfermagem, Sistematização da assistência de Enfermagem, Fundamentos do cuidado de Enfermagem, Enfermagem na atenção básica e Gerência do cuidado em saúde e em Enfermagem. Nas disciplinas, Saúde coletiva, Enfermagem clínica e cirúrgica, Saúde da mulher, e Enfermagem da criança e do adolescente, nota-se que os conteúdos teóricos e práticos são intercalados durante o semestre, mas ainda assim, eles não ocorrem juntos, o que se verifica é a alternância, ao longo do semestre, entre períodos de atividades teóricas e atividades práticas.

Outro aspecto que merece ser ressaltado na fala de Di12 refere-se ao pouco tempo de prática em relação à teoria, o que não favorece um preparo maior para o exercício da profissão. Nesse contexto, outros discentes reafirmam isso e acrescentam que o ritmo é acelerado:

Olha, eu sinto que sim, não sinto que eu tivesse dificuldades nessa união do teórico com prático, eu acho que o prático às vezes ele fica meio corrido, a gente perde oportunidade de pegar mais prática no campo mesmo, tanto que a gente chega nos últimos períodos, a gente sente a sensação de que não sabe nada [...]. Tem certos temas que já foram trabalhados por anos e anos dentro das disciplinas que vai desde Fundamentos, Hipertensão e Diabetes, são importantes? São. Mas, acaba tendo uma atenção muito extensa para elas, sendo que poderiam ser dadas dentro da prática, e aí aumentar a prática da gente, então eu acho que é nesse sentido, e aí a gente fica tomado por aquela correria, para poder fazer procedimento, fazer procedimento [...] (Di6).

Entre conteúdo teórico e conteúdo prático... [...] eu acho que a faculdade oferece pouca prática para o aluno, tem muita, tem bastante teoria, mas tem pouca prática das coisas, dentro da faculdade mesmo, sem ser já com o paciente e tal, por exemplo, a Semiologia que a gente tem, é muito pouco tempo para treinar isso [...] Então, eu acho que no currículo podia ser trabalhado isso da prática mesmo, de inserir mais prática e inserir algumas disciplinas que são fundamentais e a gente não tem, por exemplo, Primeiro Socorros, o nosso Primeiro Socorros é muito fraco, às vezes a gente precisa de Primeiro Socorros em um hospital em alguma coisa, a gente não... Ninguém se sente capacitado para fazer alguma coisa com os Primeiros Socorros oferecido na faculdade, e ele não é uma matéria obrigatória é uma matéria optativa [...] (Di11).

A falta de harmonia na distribuição da carga horária teórica e prática mostra que se perde muito tempo teorizando sobre conteúdos que poderiam ser trabalhados no cenário de prática. Chama-se atenção para o fato de Di11 destacar o fraco ensino de Primeiros Socorros, uma vez que a disciplina não capacita "ninguém", ou seja, não propicia aos estudantes habilidades $e$ competências para atuar com segurança na vigência de situações que requer a prestação de primeiros socorros. Além disso, o discente critica o fato de a disciplina ser optativa.

A reivindicação por uma distribuição mais equilibrada entre conhecimento teórico e prático se fortalece nos discursos, a seguir:

Em relação ao currículo, se ele tem permitido a integração entre conteúdo teórico e conteúdo prático, eu acredito que, muitas vezes, as disciplinas elas oferecem isso, mas eu acredito que o conteúdo prático, muitas vezes, ele é bem reduzido, então a gente não consegue, desenvolver muito bem o que é dado em teoria. Então eu acredito que o currículo falta muito em questão de conteúdo prático. [...] Às vezes, tem duas semanas de prática, sendo que a gente tem o semestre todo, ou então a disciplina é reduzida em apenas dois meses e nisso a gente tem que fazer tanto a prática como a teoria, então eu acho que podia melhorar um pouco nessa questão. [...] Talvez iniciar um pouco antes essa questão da gente entendero que o enfermeiro faz na profissão, não deixar só lá para o final, até então a gente fica muito perdido durante a graduação (Di10).

Essa questão de integrar o conteúdo teórico com o prático eu acho que permite [...] apesar de o currículo ter aumentado para cinco anos, eu peguei a primeira turma de cinco anos, [...] eu acho que ainda é muito pouco para passar tanta... Tem umas disciplinas que são muito extensas, a teórica vai muito corrida, aí a prática também, tem hora que a gente sai da prática sem conseguir fazer algumas coisas, deixa a desejar alguns procedimentos mesmo [...] (Di9).

É importante realçar que Di10 critica a forma como determinada disciplina é planejada no semestre, este deveria ser mais bem aproveitado para garantir uma maior diluição dos 
conteúdos. Outra crítica se refere à inserção tardia da prática, pois somente no final do curso é que se torna possível descobrir a identidade da profissão.

\section{DISCUSSÃO}

A partir da análise dos discursos, observa-se que, para alguns docentes, a efetivação da articulação teórico-prática está fundamentada na compreensão de que se trata de uma unidade indissolúvel, que abriga a ideia de um movimento simultâneo, no qual a prática não é apenas a aplicação da teoria, mas o seu ponto de partida e de chegada. ${ }^{8}$ Desta forma, o agir pedagógico desses docentes vai ao encontro da proposta curricular do curso, que não só preconiza essa indissolubilidade, como também, a considera imprescindível para suplantar o enfoque racionalista e positivista que mantém a teoria e a prática como polos dicotômicos. ${ }^{17}$

Reitera-se que, na visão de unidade indissolúvel, a teoria não comanda a prática e não a orienta no sentido de torná-la dependente das ideias, como também não se dissolve na prática, anulando-se a si mesma. A prática, por seu lado, não significa a aplicação da teoria ou uma atividade dada e imutável, então, conceber a relação teórico-prática como unidade indissolúvel, implica reconhecer que imanente a qualquer prática existe sempre uma teorização, por mais obscura e indefinida que se apresente, por esse prisma, não faz sentido pensar em teoria seguida de prática, da mesma forma que não faz sentido pensar na prática sem teoria. ${ }^{12}$ Nessa perspectiva, teoria e prática se produzem mutuamente, marcando a impossibilidade de separação e de hierarquização. ${ }^{18}$

Contudo, nos discursos dos demais docentes e nos discursos dos discentes, evidencia-se o predomínio do pensamento de que o saber antecede o fazer, ou seja, os conhecimentos estão disponíveis no mundo para ser adquiridos e posteriormente aplicados a uma dada realidade. ${ }^{19} \mathrm{Nessa}$ perspectiva, os espaços da prática são reduzidos a meros receptores de conteúdos fragmentados estudados em sala de aula. Além disso, esses espaços são percebidos como instâncias que têm pouco a oferecer no que diz respeito à articulação de novas aprendizagens e à produção e socialização do conhecimento. ${ }^{20}$ Dessa forma, a prática propriamente não inventa, não cria e não introduz situações novas, apenas comprova a teoria, não sendo vista como a sua fonte desafiadora. ${ }^{8}$

É importante ressaltar que outros estudos que buscaram analisar o processo de formação do enfermeiro, encontraram resultados semelhantes no que diz respeito às limitações curriculares para superar a dicotomia teoria e prática, sendo essa dicotomia um dos maiores desafios da formação em saúde. .1,22 $^{2}$

Veiga-Netto, ${ }^{12}$ contribui com essa discussão ao afirmar que é preciso combater argumentos que contribuem para a polarização entre teoria e prática, pois, para o autor, negar a teorização e apostar tudo na prática indica um espontaneísmo epistemológico míope e grosseiro. Por outro lado, colocar todas as fichas na teoria não passa de pedantismo e encastelamento acadêmico. Assim, a opção por um desses extremos deve ser combatida, pois só leva à estagnação e à impossibilidade de qualquer ação educativa digna desse nome.

É imprescindível, então, que a articulação teórico-prática aconteça numa relação dialética de forma que a ordem em que teoria e prática aparecem não importa tanto, mas sim a natureza de seus elementos e a sua combinação. ${ }^{23,24}$ Para tanto, é preciso superar a crença de que o conhecimento é construído de forma progressiva e linear, sendo necessário compreender que, na maioria das vezes, o conhecimento se constrói é na desordem e no caos. ${ }^{25}$

Nessa perspectiva, a articulação teórico-prática pode ser pensada a partir do princípio da recursão organizacional ou do anel recursivo de Morin. ${ }^{26}$ Tal princípio se opõe à ideia linear de causa/efeito, de produto/produtor, de estrutura/superestrutura, uma vez que tudo o que é produzido volta-se sempre sobre o que o produz num processo cíclico autoconstitutivo, auto-organizador e autoprodutor. Por esse prisma, os indivíduos produzem a sociedade que produz os indivíduos, ou seja, os indivíduos são, a um só tempo, produtos e produtores. De forma análoga, teoria e prática fazem parte de um circuito no qual uma produz e é produzida pela outra reciprocamente.

Outro aspecto que merece discussão refere-se à distribuição desigual entre as cargas horárias teórica e prática. Nos seus discursos, os discentes explicitam a insatisfação com o tempo reduzido nos campos de prática. Constata-se aí uma supervalorização da teoria em detrimento da prática, presente em grande parte dos cursos universitários e queixa frequente de alunos, o que revela a inadequada utilização do tempo no decorrer da disciplina e a falta de reflexão sobre os conceitos teóricos no momento da prática. ${ }^{27}$

Nessa direção, vale ressaltar que a dissociação teoria e prática tem sido recorrente, sobretudo nos campos que incidem mais diretamente sobre a prática social, ou seja, nas chamadas áreas aplicadas. ${ }^{8} \mathrm{~A}$ Enfermagem como prática social, que tem como produto final o cuidado relacionado à pessoa, nos diferentes momentos do processo de saúde/doença, ${ }^{28}$ quando pautada nessa dissociação, se dá de forma acrítica, por isso, com reduzido impacto para provocar mudanças na realidade social. ${ }^{11}$ No ensino de Enfermagem, a articulação teórico-prática torna-se particularmente importante quando se almeja também um ensino interdisciplinar, pois a ausência dessa articulação tem sido apontada como fator limitante para a plena aplicação da interdisciplinaridade. ${ }^{29,30}$

Dessa forma, é essencial que a efetivação da articulação teórico-prática como unidade indissolúvel ocorra em todos os componentes curriculares, já que esta é a alternativa para a vinculação do pensar e do agir, da unicidade, da inventividade e da irrepetibilidade da prática ${ }^{28}$ assistencial do enfermeiro.

Nesse contexto, para fazer frente ao pensamento cartesiano que, ainda permeia a Enfermagem contemporânea, ${ }^{31}$ defende-se a pertinência da inserção do pensamento complexo nos currículos dos cursos de Enfermagem. A teoria do pensamento complexo, defendido por Morin, ${ }^{26}$ aspira à articulação entre os campos disciplinares que são desmembrados pelo pensamento disjuntivo 
o qual isola o que separa e oculta tudo o que religa, interage e interfere. O complexo ou complexus designa aquilo que é tecido junto, integrando, o mais possível, os modos simplificadores, reducionistas e unidimensionais de pensar e de compreender a realidade. Tal pensamento vai ao encontro da compreensão do ser humano como um ser complexo, por isso o cuidado direcionado a ele é também uma ação complexa, o que requer um trabalho interdisciplinar, disposto a religar saberes frente aos diversos problemas de saúde e condições de vidados seres humanos. ${ }^{32}$

Dessa forma, entende-se que o pensamento complexo traz outra racionalidade epistemológica para o campo educacional, especialmente para aquele inerente à formação do enfermeiro, pois tal formação envolve múltiplas dimensões da vida humana - intelectual, afetiva, social, estética, cultural, política e múltiplos conhecimentos de várias áreas. ${ }^{33}$

Portanto, considerando-se que a formação em saúde é um vetor fundamental na produção de saberes e fazeres modeladores das formas de existência, ${ }^{19}$ cabe a ela garantir um ensino integrado aos futuros enfermeiros. Logo, esse ensino deve aproximar, ao longo de todo o processo formativo, o mundo do ensino e o mundo do trabalho, conforme recomendação das DCN para os cursos de Enfermagem. ${ }^{4}$ Isso porque não é possível por meio de atividades pontuais no currículo, promover no discente a capacidade crítica e reflexiva almejada para atuar com compromisso ético e social no processo saúde-doença dos indivíduos e da coletividade. ${ }^{21}$

Somente um ensino integrado tem condições de desenvolver nos estudantes as competências e habilidades necessárias para atuar no SUS, que é um sistema complexo, pois abrange diferentes níveis de atenção, possui fontes diversificadas de financiamento, profissionais de diversas formações e especialidades, disparidade estrutural e de recursos tecnológicos, além da variedade do público usuário desse sistema. ${ }^{34}$

\section{CONSIDERAÇÕES FINAIS E IMPLICAÇÕES PARA A PRÁTICA}

Neste estudo, os resultados apresentados apontam que há fragilidades na efetivação da articulação teórico-prática no currículo do curso de Enfermagem aqui investigado, evidenciando as dificuldades das IES em conseguir efetivar as proposições das DCN para os cursos de Enfermagem.

As fragilidades identificadas relacionam-se com o planejamento das disciplinas, que mantém a lógica da teoria precedendo à prática em detrimento de um planejamento que contemple a junção teoria-prática acontecendo sincronicamente, sem a primazia de uma sobre a outra, e também, com a falta de harmonia na distribuição das cargas horárias teóricas e práticas, com tempo reduzido do discente nos campos de prática.

Essas fragilidades indicam que o processo de formação do enfermeiro ainda segue o modus operandi do ensino fragmentado. Não obstante, a consecução da articulação teórico-prática é uma necessidade e precisa ser perseguida, já que a disjunção entre o pensar e o fazer corrobora para a manutenção de práticas assistenciais desprovidas de criticidade e de cientificidade, o que limita, dessa forma, a capacidade de um agir reflexivo.

Embora os resultados aqui apresentados sejam limitados na sua temporalidade, considera-se que as mudanças no processo de formação do enfermeiro não dependem, exclusivamente, de novos desenhos curriculares, mas, sobretudo, do envolvimento e do compromisso de cada docente na consecução dessas mudanças. Dessa forma, as dicotomias ainda vigentes no ensino de enfermagem, só serão suplantadas, se houver uma busca constante pelo pensamento complexo, capaz de contextualizar e interconectar as partes ao todo e vice-versa.

As limitações do presente estudo residem no fato de se tratar de um estudo de caso único que buscou aprofundar na efetivação da articulação teórico-prática, que representa uma das muitas dimensões que compõem o currículo, além de considerar, como participantes, os discentes de apenas uma turma e um docente de cada área. Outra limitação do estudo é o fato de o tempo médio das entrevistas ter sido relativamente curto, o que reduziu o volume de material a ser analisado. Nesse sentido, vislumbra-se a necessidade de novas pesquisas que possam apontar as lacunas existentes no processo de formação do Enfermeiro, pois só assim, será possível a construção de proposições eficazes no aprimoramento do ensino de enfermagem e, por conseguinte, na melhoria da qualidade da assistência prestada pelos profissionais dessa área.

\section{CONTRIBUIÇÕES DOS AUTORES}

Concepção e delineamento das etapas de pesquisa. Análise de dados e interpretação dos resultados. Redação e revisão crítica do manuscrito. Aprovação da versão final do artigo. Responsabilidade por todos os aspectos do conteúdo e a integridade do artigo publicado. Vânia Aparecida da Costa Oliveira.

Concepção da pesquisa e delineamento das etapas de pesquisa. Revisão crítica do manuscrito. Aprovação da versão final do artigo. Responsabilidade por todos os aspectos do conteúdo e a integridade do artigo publicado. Maria Flávia Gazzinelli.

Redação e revisão crítica do manuscrito. Aprovação da versão final do artigo. Responsabilidade por todos os aspectos do conteúdo e a integridade do artigo publicado. Patrícia Peres de Oliveira.

\section{EDITOR ASSOCIADO}

Cristina Rosa Soares Lavareda Baixinho

\section{REFERÊNCIAS}

1. Costa RR, Medeiros SM, Santos VEPS, Feiião AR, Bosco Filho J, Araújo MS. Positivism and complexity: interfaces and influences in the educational context in the undergraduate nursing program. Rev. Baiana Enferm. [Internet]. 2017; [citado 2018 dez 10];31(1):e17067. Disponível em: https://portalseer.ufba.br/index.php/enfermagem/article/ view/17067/14113

2. Fernandes JD, Silva RMO, Teixeira GA, Florencio RMS, Silva LS, Rebouças LCC. Aderência de cursos de graduação em enfermagem 
às diretrizes curriculares nacionais na perspectiva do Sistema Único de Saúde. Esc Anna Nery. 2013;17(1):82-9. http://dx.doi.org/10.1590/ S1414-81452013000100012.

3. Brehmer LCF, Ramos FRS. The experiences of the reorientation program for professional training in nursing: advances and challenges. Texto Contexto Enferm. 2017;26(2):e3100015. http://dx.doi.org/10.1590/010407072017003100015.

4. Resolução CNE/CES no 3 , de 7 de novembro de 2001 (BR). Diretrizes Curriculares Nacionais do Curso de Graduação em Enfermagem. Diário Oficial da União, Brasília (DF), 9 nov 2001.

5. Marchioro D, Ceratto PC, Bitencourt JVOV, Martini JG, Silva Filho CC, Silva TG. Estágio curricular supervisionado: relato dos desafios encontrados pelos (as) estudantes. Arq. Ciênc. Saúde UNIPAR [Internet]. 2017 [citado 2018 dez 11];21(2):119-22. Disponível em: http://www. revistas.unipar.br/index.php/saude/article/view/5912/3460

6. Ribeiro JF, Costa JML, Silva MAC, Luz VLE, Veloso MV, Ribeiro $\mathrm{ALI}$ et al. Prática pedagógica do enfermeiro na docência do ensino superior. Rev Enferm UFPE Online. 2018;12(2):291-302. http://dx.doi. org/10.5205/1981-8963-v12i2a25129p25129-25129-2018.

7. Oliveira PP, Amaral JG, Barbosa TAV, Doris VFA, Rodrigues AB, Onofre PSC. Knowledge of nursing students with technical-professional training on Alzheimer's disease. Rev Enferm UFPE OnLine [Internet]. 2013; [citado 2018 dez 11];7(2):527-36. Disponível em: http://10.5205/ reuol.3073247911LE.0702201327

8. Candau VM. Rumo a uma nova didática. 24를 ed. Petrópolis: Vozes; 2014.

9. Fernandes JD, Rebouças LC. Uma década de Diretrizes Curriculares Nacionais para a graduação em Enfermagem: avanços e desafios. Rev Bras Enferm. 2013 set;66(Spec):95-101. http://dx.doi.org/10.1590/ S0034-71672013000700013. PMid:24092316.

10. Fernandes MNS, Beck CLC, Weiller TH, Coelho APF, Prestes FC, Donaduzzi DSS. Satisfação e insatisfação de residentes multiprofissionais em saúde na perspectiva da formação. Rev. Baiana Enferm. 2017;31(3):e18344. http://dx.doi.org/10.18471/rbe.v31i3.18344.

11. Trevisan DD, Minzon DT, Testi CV, Ramos NA, Carmona EV, Silva EM. Formação de enfermeiros: distanciamento entre a graduação e a prática profissional. Cienc. Cuid. Saúde. 2013 abr/jun;12(2):331-7. http://dx.doi.org/10.4025/cienccuidsaude.v12i2.19643.

12. Veiga-Neto A. Anotações sobre as relações entre teoria e prática. Educ. Foco. 2015;20(1):113-40. http://dx.doi.org/10.22195/24475246v20n120152914.

13. Cunha C, Macedo A, Vieira I. Percepções dos estudantes de enfermagem sobre os processos formativos em contexto de ensino clínico. Rev. Enf. Ref. 2017 mar;4(12):65-74. http://dx.doi.org/10.12707/RIV16072.

14. Yin RK. Estudo de caso: planejamento e métodos. $2^{\underline{a}}$ ed. Porto Alegre: Bookman; 2015.

15. Poupart J, Deslauriers JP, Groulx LH, Laperriere A, Mayer R, Pires A. A pesquisa qualitativa: enfoques epistemológicos e metodológicos. Petrópolis: Vozes; 2014.

16. Magalhães I, Martins AR, Resende VM. Análise de discurso crítica: um método de pesquisa qualitativa. Brasília (DF): UNB; 2017.

17. Universidade Federal de Minas Gerais. Escola de Enfermagem. Projeto pedagógico do curso de graduação em Enfermagem da Escola de Enfermagem da Universidade Federal de Minas Gerais. Belo Horizonte: UFMG; 2006.

18. Vázquez AS. Filosofia da práxis. $2^{\mathrm{a}}$ ed. Rio de Janeiro: Paz e Terra; 1977.
19. Pinheiro R, Silveira RP, Lofego J, Silva-Júnior AG, organizadores Integralidade sem fronteiras: itinerários de justiça, formativos e de gestão na busca por cuidado. Rio de Janeiro: Cepesc/IMS/UERJ/ Abrasco; 2012.

20. Fagundes NC, Burnham TF. Discutindo a relação entre espaço e aprendizagem na formação de profissionais de saúde. Interface. 2005 fev;9(16):105-14. http://dx.doi.org/10.1590/S1414-32832005000100009.

21. Brehmer LC, Ramos FRS. O modelo de atenção à saúde na formação em enfermagem. Interface. 2016 jan/mar;20(56):135-45. http://dx.doi. org/10.1590/1807-57622015.0218.

22. Moraes BA, Costa NAS. Understanding the curriculum the light of training guiding health in Brazil. Rev Esc Enferm USP. 2016 jun;50(Spec):9-16. http://dx.doi.org/10.1590/S0080-623420160000300002. PMid:27384270.

23. Marques JP, Miranda ARA. A importância da articulação teoria e prática nos percursos formativos dos professores de história. História \& Ensino. 2016 jul/dez;22(2):137-63. http://dx.doi.org/10.5433/22383018.2016v22n2p137.

24. Pandovani O, Correa AK. Currículo e formação do enfermeiro: desafios das universidades na atualidade. Sau. \& Transf. Soc. [Internet]. 2017 maio/ago [citado $2018 \mathrm{dez}$ 11];8(2):112-9. Disponível em: http:// incubadora.periodicos.ufsc.br/index.php/saudeetransformacao/article/ view/3841/4990

25. Bernstein B. Pedagogy, symbolic control and identity. Madrid: Ediciones Morata; 1998.

26. Morin E. Introdução ao pensamento complexo. $5^{\underline{a}}$ ed. Porto Alegre: Sulina; 2015.

27. Franco AC, Boog MCF. Relação teoria-prática no ensino de educação nutricional. Rev Nutr. 2007 nov/dez;20(6):643-55. http://dx.doi.org/10.1590/ S1415-52732007000600007.

28. Zoboli ELCP, Schveitzer MC. Nursing values as social practice: a qualitative meta-synthesis. Rev Lat Am Enfermagem. 2013;21(3):695-703. http:// dx.doi.org/10.1590/S0104-11692013000300007. PMid:23918014.

29. Puppin MAP, Sabóia VM. Interdisciplinarity as a structurer in the training and health care process. Rev Enferm UFPE On Line [Internet]. 2017; [citado 2018 dez 11];11(Supl. 10):4065-71. Disponível em: https:// periodicos.ufpe.br/revistas/revistaenfermagem/article/view/231166/25129

30. Vendrusculo AP, Filippin NT, Cunha TA, Schetinger MRC. Interdisciplinaridade na percepção de docentes de ensino superior. Educere Revista da Educação. 2019 jul/dez;19(2):291-312. http://dx.doi.org/10.25110/ educere.v19i2.2019.7043.

31. Nunes EC, Silva LW, Pires EP. Nursing professional education: implications of education for transpersonal care. Rev Lat Am Enfermagem 2011;19(2):252-60. http://dx.doi.org/10.1590/S0104-11692011000200005. PMid:21584370.

32. Santos SSC. Educação em enfermagem e a complexidade. Contexto \& Educação. 2013; [citado 2018 dez 11];20(73-74):103-17. Disponível em: https://www.revistas.unijui.edu.br/index.php/contextoeducacao/ article/download/1125/880

33. Nascimento ES, Santos GF, Caldeira VP, Teixeira VMN. Formação por competência do enfermeiro: alternância teoria-prática, profissionalização e pensamento complexo. Rev Bras Enferm. 2003 jul/ago;56(4):447-52. http://dx.doi.org/10.1590/S0034-71672003000400030. PMid:14699774

34. Arruda C, Lopes SGR, Koerich MHAL, Winck DR, Meirelles BHS, Mello ALSF. Health care networks under the light of the complexity theory. Esc Anna Nery. 2015;19(1):169-73. http://dx.doi.org/10.5935/14148145.20150023.

aPesquisa extraída da tese de doutorado com o título de "Currículo do curso de enfermagem da Universidade Federal de Minas Gerais (EEUFMG): perspectiva de docentes e discentes", defendida por Vânia Aparecida da Costa Oliveira, sob a orientação de Maria Flávia Gazzinelli. Programa de Pós-Graduação em Enfermagem- Escola de Enfermagem. Universidade Federal de Minas Gerais. 2016 